\title{
SOUND-MUSIC EXPERIENCES AND MATERNAL SENSITIVITY FOLLOWING PRETERM BIRTH: CONTRIBUTIONS FOR THE MODEL OF FAMILY-CENTERED CARE
}

\author{
Maria Eduarda S. Carvalho \\ CESEM-NOVA-FCSH, Portugal \\ educarte@sapo.pt \\ João M. R. M. Justo \\ Faculdade de Psicologia, Universidade de Lisboa, Portugal \\ Helena Rodrigues \\ CESEM-NOVA-FCSH, Portugal
}

Fecha de Recepción: 21 Mayo 2018

Fecha de Admisión: 1 Octubre 2018

\begin{abstract}
Introduction: The model of Family-Centered Care strengthens the parents' active role at the caring for the newborn baby. Prenatal maternal sound-music sensitivity increases at the third trimester of pregnancy and shows to be a good predictor of prenatal maternal attachment. Method: preterm mothers $(N=36)$ were interviewed about clinical and sociodemographic features as well as about their sound-music experiences after and before preterm delivery. Correlations between sociodemographic, clinical and sound-music experiences were performed. Results: sound-music experiences after preterm birth were associated with memories of sound-music experiences during pregnancy and seem to be influenced by previous abortions as well as by babies' variables (gestational age at birth, weight at birth and chronological age at observation). Conclusion: The assessment of maternal sound-music experiences following preterm birth may be useful in an innovative way to strength the model of Family-Centered Care underlining the mothers' active role at the attention directed to the vulnerable baby.
\end{abstract}

Keywords: preterm dyads; maternal sound-music experiences; maternal voice; memories of pregnancy; family-centered care

\section{BACKGROUND}

A preterm delivery always induces vulnerabilities in preterm dyads among which we can find difficulties for the self-regulation of the baby and difficulties of maternal perception about the baby's behavioral signs. These vulnerabilities may play a negative role at the organization of the interactions between the baby and the mother.

The beginning of maternal perception about fetal movements is an important landmark for the 


\section{SOUND-MUSIC EXPERIENCES AND MATERNAL SENSITIVITY FOLLOWING PRETERM BIRTH: CONTRIBUTIONS FOR THE MODEL OF FAMILY-CENTERED CARE}

origin of maternal-fetal differentiation (Colman \& Colman, 1971) and for sensorial and emotional proto-dialogs before birth. Maternal subjectivity about fetal movements favors the development of the imaginary baby (Lebovici \& Stóleru, 1983). After birth, maternal memories about the imaginary baby may be compromised by the occurrence of a pre-term delivery (Fleck \& Piccinini, 2013).

Some studies showed that prematurity may affect the bond as well as mother-infant interaction (Forcada-Guex, Pierrehumbert, Borghini, Moessinger, \& Muller-Nix, 2006; Korja, Latva, \& Lehtonen, 2012). However, scientific literature is not consistent at this regard. A meta-analysis (Bilgin \& Wolke, 2015) based in 34 studies published between 1980 and 2013 didn't found significant differences about maternal sensitivity and responsiveness between pre-term mothers and mothers at term about their interactions with the babies during the first years of life. Other studies (Brandon et al., 2008; White, McCorry, Scott-Heyes, Dempster, \& Manderson, 2008) also failed to find differences in pre-natal attachment when comparing pregnant women with risk factors according to the seriousness of risks. The same is concluded when comparing pregnant women with risks of maternal nature vs. fetal nature. Another study with Portuguese pregnant women observed by the third trimester (Camarneiro \& Justo, 2014) reaches the conclusion that although pre-natal attachment plays an important role at the psychological experience of pregnancy and labor it does not seems to have impact in obstetrical pathology nor in the delivery outcome. More than that, pregnant women with higher levels of prenatal attachment had babies presenting a higher probability of having health problems. This suggests that pre-natal attachment probably is a protective factor that favors the bonding between mother and baby in vulnerable dyads. However literature is also not consistent about the way pregnant women attach to their fetuses while in a context of vulnerability; differences have been observed according to mothers' culture (Bielawska-Batorowicz \& Siddiqui, 2008).

A previous study with Portuguese pregnant women (Carvalho, 2011; Carvalho \& Justo, 2013, 2014) showed that the sound-music sensitivity of the pregnant women increases at the third trimester of pregnancy and is a significant predictor of maternal pre-natal attachment. This observation reinforces results observed in other studies of music-therapy in perinatality. Literature underlines the benefits of maternal singing (Carolan, Barry, Gamble, Turner, \& Mascareñas, 2012; Standley, 2012; Filippa et al., 2017). During skin-to-skin contact maternal singing is able to decrease anxiety (Arnon, Diamant, Bauer, Regev, Sirota, \& Litmanovitz, 2014). This result was also obtained by Pölkki and Korhonen (2014) who also observed benefits in neonatal attachment. Furthermore, benefits in physiological and behavioral stability were found when maternal alive speech or singing were delivered to pre-term babies' (Filippa, Devouche, Arioni, Imberty, \& Gratier, 2013; Standley, 2012). Other studies pointed out positive impacts of maternal singing in pre-term mothers' adjustment (Cevasco, 2008) and of the use of song of kin by parents in neonatal care (Loewy, 2015).

Our general hypothesis is that, after a preterm birth, the access to maternal sound-music experience may help to develop the knowledge about preterm mothers' behavior, attitudes and sensitivity in a context of neonatal care. This possibly will help to expand our understanding about the maternal intuitive ability for the reading of the baby's signals; so this underlines the need for neonatal care able to enhance maternal sensibility. The access to maternal sound-music experiences following preterm birth will help to build good practices inspired in the neonatal family-centered care model (Ramezani, Shirazi, Sarvestani, \& Moattari, 2014).

\section{METHOD}

After the approval of the Ethical Committee of Central Lisbon Hospital Center and also after the signed informed consent, preterm mothers were recruited $(N=50)$ in order to participate in a study for the observation of vocal interaction during skin-to-skin condition. Due to issues of the hospital routines or for personal motives, some participants $(n=10)$ were not able to participate in the study 
procedures. During the protocol of the study 4 participants were not included because of intercurrences during the video recording and 2 did not answer the questionnaires. Between May 2016 and April 2017, after the observation, 34 participants were interviewed at the Intermediate Neonatal Care Unit of Maternidade Dr. Alfredo da Costa, central maternity hospital in Lisbon. This interview was based in a Sociodemographic and Clinical Questionnaire as also in a Questionnaire about SoundMusic Experience Before and After Birth (QSMEBAB). This questionnaire originally created for this study included 41 items about maternal behavior of sound-music and vocal nature as well as about maternal perceptions related with the baby's responses to the sound-music environment. Among the 41 items, 20 were on the domain of pregnancy (e.g.: "... I used to sing frequently to my baby") and 21 were on the afterbirth domain (e.g.: "... I feel that my baby becomes calmer when I sing to him"). Answers were recorded in Likert scales varying from 0 (I completely disagree) to 5 (I completely agree). Sample: mothers were predominantly Portuguese $(n=26)$, in adult age $(M=34$, min. $=21$, max. $=48)$, had a university level of education $(M=15.33)$, were mostly married $(n=23)$ and in many cases had no previous sons $(n=22)$. Male babies $(n=20)$ were slightly more frequent than female babies $(n=16)$. At birth, babies had in average 30 weeks and 4 days of gestational age (min. $=25.43$, max. $=34.43)$ and weight varied between $590 \mathrm{~g}$ and $2017 \mathrm{~g}(\mathrm{M}=1265.47 \mathrm{~g})$. At the moment of observation, babies' chronological age was 26.5 days in average $(\min .=4$, max. $=81$ ) and weight was between $1060 \mathrm{~g}$ and $2185 \mathrm{~g}(\mathrm{M}=1538.05 \mathrm{~g})$.

Relatively to abortions, 13 mothers had spontaneous interruptions of pregnancy, 6 had a history of voluntary interruptions and 13 reported having had interruptions of pregnancy due to medical advice. At the last pregnancy, there were 10 cases of twin pregnancy. All pregnancies were desired and only 5 were not planned. About births, only 12 happened after a vaginal delivery; for 19 cases delivery was triggered spontaneously and in 15 cases it was induced (in 2 cases this information was not obtained).

\section{RESULTS}

Based on the data from the QSMEBAB, preliminary factor analysis were performed for items related to the gestation domain and to the afterbirth domain. About memories of pregnancy, two factors were identified. The first factor, F1-P, was composed by 11 items $(5,6,7,8,9,11,14,17,18$, $19,20)$ and had a good internal consistency $(=.851)$. This factor was designated as "Maternal Behaviors and Perceptions about Fetal Reactions to Sound-Music Environment" (e.g.: ... I used to sing frequently, ... I felt that my baby liked or disliked some music). The second factor, F2-P, composed by 3 items $(1,2,3)$ also had a good internal consistency $(=.826)$. This factor was designated as "Memories about the Prenatal Sound-Music Environment" (e.g.: ... the sound environment was calm). Relatively to the afterbirth domain we also found two factors. The first factor, F1-AB, composed by 8 items $(31,32,33,35,36,37,38,41)$, had a good internal consistency $(=.843)$. This factor was designated as "Maternal Vocal Behaviors and the Intention for Self-Regulation" (e.g.: ... singing helps me to become less anxious, ... during Kangaroo Care, I sing frequently for my baby). The second factor, F2-AB, composed by 5 items $(21,22,23,25,27)$ had an acceptable internal consistency $(=.760)$. This factor was designated as "Maternal Sensitivity about the Environmental Sound of the Neonatal Intensive Care Unit for and Intention for Self-Regulation" (e.g.: ... I often hear music to calm me down, ... I feel that noises upset my baby).

In order to study relationships between, on one hand, sociodemographic and clinical variables and, on the other hand, variables of sound-music nature, Pearson correlations were performed. Concerning maternal age, several positive and significant correlations were observed, namely with: 1) spontaneous abortions $(R=.570, p=.000), 2)$ abortions due to medical advice $(R=.431, p=$ 


\section{SOUND-MUSIC EXPERIENCES AND MATERNAL SENSITIVITY FOLLOWING PRETERM BIRTH: CONTRIBUTIONS FOR THE MODEL OF FAMILY-CENTERED CARE}

$.028)$ and 3 ) total of abortions $(R=.469, p=.005)$. These results suggest that the higher the maternal age the higher is the number of abortions. More than that, we also found positive and significant correlations between the number of successful years of maternal education and: 1 ) the number of gestational weeks at the beginning of maternal perception of fetal movements $(R=.495, p=.002$ ) and 2$)$ baby's gestational age at birth $(R=.383, p=.021)$. It is concluded that the higher is maternal education the later is the beginning of maternal perception of fetal movements and higher is the number of baby's gestational weeks at birth (so, less prematurity). Probably, mothers with higher levels of education are more focused in their intellectual activities and less alert relatively to the sensorial aspects of the fetus. Furthermore, they also may be more closely supported by their physicians enhancing a later occurrence of delivery. Negative and significant correlations were detected between the number of gestational weeks at the beginning of the maternal perception of fetal movements and: 1) the number of previous sons ( $R=-.366, p=.028), 2)$ the number of abortions due to medical advice $(R=-.401, p=.042)$ and 3$)$ the number of fetus at the last pregnancy $(R=-.390, p=$ .019). Results suggest that maternal perception of fetal movements happens earlier in mothers with previous maternal experience. Interruptions due to medical advice seem to induce maternal hypervigilance and for that reason maternal perception of fetal movements happens earlier. Results also show that the higher the number of fetus the earlier the beginning of maternal perception of fetal movements.

The number of kangaroo care performances related by the mother is negatively and significantly correlated with gestational age at birth $(R=-.436, p=.008)$ and also with weight at birth $(R=-$ $.594, p=.000)$ and positively correlated with the baby's chronological age at the moment of the observation $(R=.406, p=.014)$. Results show that the higher the time of the baby's extra-uterine life the higher the opportunity for the mothers to perform kangaroo care and so the higher the frequency of maternal interaction with the baby in cases of early prematurity.

Relatively to variables about sound-musical maternal experience a positive and significant correlation between $\mathrm{F} 1-\mathrm{AB}$ and $\mathrm{F} 1-\mathrm{P}(\mathrm{R}=.729, \mathrm{p}=.000)$ was observed. This suggests that maternal vocal behaviors directed to the baby after birth are associated with memories of maternal soundmusic behaviors and with maternal perceptions about the fetus when reacting to the sound-music environment.

Concerning the correlations between sociodemographic-clinic variables and sound-music experience variables, it was found a negative and significant correlation between spontaneous abortions and F2-AB ( $R=-.356, p=.039)$ as well as a positive correlation between spontaneous abortions and $\mathrm{F} 2-\mathrm{P}(\mathrm{R}=.368, \mathrm{p}=.032)$. Results suggest that the more the spontaneous abortions the lesser is the maternal sensitivity to the sound environment after birth and the higher the memories about prenatal sound environment. According to the content of the items, it seems that preterm mothers are trying to regulate themselves remembering a silent and calm prenatal sound environment.

Baby's gestational age at birth is negatively correlated with the value of $F 1-A B(R=-.541, p$ $=.001)$ and with the value of $F 1-P(R=-.401, p=.019)$. In the same sense, it was observed a negative and significant correlation between the baby's weight at birth and F1-AB $(R=-.470, p=.005)$ and also a positive and significant correlation between the baby's chronological age and F1-AB $(R=$ $.490, p=.003)$. Results suggest that the earliest the baby is born the higher are the opportunities for the mother to interact with him within a vocal modality.

\section{CONCLUSION}

According to our hypothesis, maternal sound music experience following preterm birth seems to be an important variable for the study of maternal behavior and sensitivity in the context of neonatal vulnerability. How the mother may contribute for a contingent dialogue with her baby depends on 
three aspects: 1) the vocal intentionality directed to the baby; 2) the reading of the baby's reactions to sound-music environment and 3) the anticipation of the baby's reactions to maternal stimuli. As such, maternal sound-music experience may play an innovative role in family-centered neonatal care by promoting a strategy of contingent reading of the baby's signals while reacting to the sound environment.

Memory relatively to the onset of maternal perception about fetal movements seems to be influenced by the number of previous abortions. This memory is as earliest as higher is the number of previous abortions. This occurrence may give rise to a maternal hypervigilance toward the fetus, inducing a higher preoccupation about fetal movements. Previous abortions also seem to significantly influence maternal sound-music experience and how the mother establishes vocal contact with the baby following a preterm birth. According to results, mothers with more previous abortions seem to reveal an attitude of higher avoidance in their relationship with the Neonatal Intensive Care Unit sound environment. At the same time, they also present an idealized representation of a silent and calm prenatal sound environment. Probably, both these prenatal and postnatal attitudes emerge as ways to obtain emotional self-regulation.

From the point of view of babies' post-menstrual age, mothers that invest earlier in their babies are those whose babies were born earlier; the more premature is the birth, the more the mother seems to make contact with the baby by singing or speaking to him.

Also, reports of the frequency of sound-musical contacts between the mother and the baby after birth are significantly associated with self-report about memories of maternal sound-music experience in the prenatal period.

The present study highlights the importance of maternal awareness about the music-sound experience in the context of prematurity, reinforcing the importance of this sensory experience in the transition from pregnancy to motherhood. In addition, we think that such awareness may offer the opportunity for the confrontation between the imaginary baby and the real baby in the aftermath of a preterm birth. The maternal active role in the care delivered to the baby through the interactions of sound-music nature may become an innovative strategy for the dyads' co-regulation reinforcing the Model of Family-Centered Neonatal Care.

\section{REFERENCES}

Arnon, S., Diamant, C., Bauer, S., Regev, R., Sirota, G., \& Litmanovitz, I. (2014). Maternal singing during kangaroo care led to autonomic stability in preterm infants and reduced maternal anxiety. Acta Pædiatrica, 103, 1039-1044.

doi: 10.1111/apa.12744

Bielawska-Batorowicz, E., \& Siddiqui, A. (2008). A study of prenatal attachment with Swedish and Polish expectant mothers. Journal of Reproductive and Infant Psychology, 36(4), 373-384. https://doi.org/10.1080/02646830802426144

Bilgin, A., \& Wolke, D. (2015). Maternal sensitivity in parenting preterm children: A meta-analysis. Pediatrics, 136(1), e177-e193. http://dx.doi.org/10.1542/peds.2014-3570.

Brandon, A. R., Trivedi, M. H., Hynan, L. S., Miltenberger, P. D., Labat, D. B., Rifkin, J. B., \& Stringer, C. A. (2008). Prenatal depression in women hospitalized for obstetric risk. Journal of Clinical Psychiatry, 69(4), 635-643.

https://www.ncbi.nlm.nih.gov/pmc/articles/PMC2680504/pdf/nihms100545.pdf

Camarneiro, A. P., \& Justo, J. M. (2014). 0 contributo dos fatores psicológicos na ocorrência do parto pré-termo. International Journal of Developmental and Educational Psychology, No1-Vol.4, 113-122. http://hdl.handle.net/10451/24311 


\section{SOUND-MUSIC EXPERIENCES AND MATERNAL SENSITIVITY FOLLOWING PRETERM BIRTH: CONTRIBUTIONS FOR THE MODEL OF FAMILY-CENTERED CARE}

Carolan M., Barry M., Gamble, M., Turner, K., \& Mascareñas 0. (2012). Experiences of pregnant women attending a lullaby programme in Limerick, Ireland: A qualitative study. Midwifery, 28(3), 321-328. https://doi.org/10.1016/j.midw.2011.04.009

Carvalho, M. E., (2011). 0 bebé imaginário, as memórias dos cuidados parentais e as representações sonoro-musicais na gravidez no estudo da representação da vinculação materna prénatal e da orientação para a maternidade. Doctoral Thesis in Clinical Psychology at the Lisbon University. http://hdl.handle.net/10451/6597

Carvalho, E., \& Justo, J. M. (2013). Sensibilidade sonoro-musical na gravidez, orientação materna pré-natal e vinculação materna pré-natal. Proceedings of the "VIII Simpósio Nacional de Investigação em Psicologia Clínica”, Associação Portuguesa de Psicologia, Aveiro, Junho, 1002 $-1011$.

file:///C:/Users/jjusto/Downloads/3_Livro\%200rganizacao_atas\%20VIII\%20SNIP\%202013.pdf

Carvalho, E. \& Justo, J. M. (2014). Construção e validação da ERSMG: Escala de Representações Sonoro-Musicais na Gravidez. International Journal of Developmental and Educational Psychology. №2, Vol.1, 411-418. https://core.ac.uk/download/pdf/72043966.pdf

Cevasco A. (2008). The effects of mothers' singing on full term and preterm infants and maternal emotional responses. Journal of Music Therapy, 46(3), 273-306. https://pdfs.semanticscholar.org/ce1e/d0e0c16d2b3eb6aec93f73a6707ae89a5d5a.pdf

Colman, A., \& Colman, L. (1971). Pregnancy: the psychological experience. New York: Herder and Herder.

Filippa, M., Devouche, E., Arioni, C., Imberty, M., \& Gratier, M. (2013). Live maternal speech and singing have beneficial effects on hospitalized preterm infants. Acta Paediatrica, 102, 1017-1020. doi: 10.1111/apa.12356.

Filippa, M., Panza, C., Ferrari, F., Frassoldati, R., Kuhn, P., Balduzzi, S., \& D’Amico, R. (2017). Systematic review of maternal voice interventions demonstrates increased stability in preterm infants. Acta Paediatrica, 106(8), 1220-1229.

doi: 10.1111/apa.13832

Fleck, A., \& Piccinini, C-A. (2013). 0 bebê imaginário e o bebê real no contexto da prematuridade: do nascimento ao 3o mês após a alta. Aletheia 40, 14-30. http://pepsic.bvsalud.org/pdf/aletheia/n40/n40a03.pdf

Forcada-Guex, M., Pierrehumbert, B., Borghini, A., Moessinger, A., \& Muller-Nix, C. (2006). Early dyadic patterns of mother-infant interactions and outcomes of prematurity at 18 months. Pediatrics, 118(1), e107-114. doi: $10.1542 /$ peds.2005-1145

Korja, R, Latva, R., \& Lehtonen, L. (2012). The effects of preterm birth on mother-infant interaction and attachment during the infant's first two years. Acta Obstetricia et Gynecologica Scandinavica, 91(2), 164-173. doi: 10.1111/j.1600-0412.2011.01304.x.

Lebovici S., \& Stoleru S. (1983). Le nourrisson, la mère et le psychanalyste: Les interactions précoces. Paris: Paidos.

Loewy, J. (2015). NICU music therapy: song of kin as critical lullaby in research and practice. Annals of the New York Academy of Sciences, 1337, 178-185. doi: $10.1111 /$ nyas. 12648

Pölkki, T., \& Korhonen, A. (2014). The effectiveness of music on pain among preterm infants in the NICU: A systematic review. The JBI Database of Systematic Reviews and Implementation Reports, 12(4), 354-373. doi:10.11124/issn.2202-4433 
Ramezani, T., Shirazi, Z. H., Sarvestani, R. SD., \& Moattari, M. (2014). Family-Centered Care in Neonatal Intensive Care Unit: A Concept Analysis. International Journal of Community Based Nursing and Midwifery, 2(4),m 268-278.

https://www.ncbi.nlm.nih.gov/pmc/articles/PMC4201206/pdf/ijcbnm-2-268.pdf

Standley, J. (2012). Music Therapy Research in the NICU: An Updated Meta-Analysis. Neonatal Network, 31(5), 311-316. doi: 10.1891/0730-0832.31.5.311

White, 0., McCorry, N. K., Scott-Heyes, G., Dempster, M., \& Manderson, J. (2008). Maternal appraisals of risk, coping and prenatal attachment among women hospitalized with pregnancy complications. Journal of Reproductive and Infant Psychology, 26(2), 74-85. https://doi.org/10.1080/02646830801918455 
